\section{Diet and the diabetic}

SIR,-We wish to comment on your leading article on this subject ( 2 October, p 781) and to report briefly the opinion of most paediatric diabetologists.

We are often in disagreement with the dietetic management recommended by diabetologists concerned with diabetic adults. As we are not permitted free expression within the International Diabetes Federation, we formed, in 1972, the International Study Group of Diabetes in Children and Adolescents. Although we have representatives of 13 countries, unfortunately Great Britain is not yet included. We therefore take this opportunity to invite our British colleagues to join us so that we may work together in this study group.

It is evident that both paediatricians and internists concerned with diabetes in childhood are trying to establish the best possible degree of metabolic control ${ }^{1}$ - that is, minimum glycosuria, normal blood lipids, avoidance of hypo- and hyper-glycaemia (which is a factor in the development of angiopa (hy), and normal growth. ${ }^{2}$ We have shown by angiofluorography that in children there exists a correlation between diabetic retinopathy and degree of control, retinopathy being present in $26 \%$ of patients with good control, $44 \%$ of those with fair control, and $67^{\circ} \%$ of those with poor control. ${ }^{3}$ We have also described for the first time the initial lesions of diabetic retinopathy, which are shown by fluorescein leakage. ${ }^{4}$

The best control is obtained through appropriate insulin therapy and an adequate distribution of the food intake but not through dietetic restrictions. It is false and arbitrary to pretend that good control "can be achieved only by maintaining the daily carbohydrate allowance constant." Somogyi and Goldwasser $^{5}$ proved that there was no parallelism between grams of glucose utilised and units of insulin injected. Lestradet ${ }^{6}$ in France and our team in Belgium ${ }^{78}$ have demonstrated that, with diabetic children and adolescents receiving an optimal dose of insulin, spontaneous variations of food intake will not alter insulin requirement or glycosuria. We have conducted a dietetic investigation ${ }^{8}$ during a summer camp for diabetic adolescents and have noted considerable daily variations in intake of total energy (10-18 MJ (2411-4289 kcal)), lipids (85-186 g), carbohydrates $(307-490 \mathrm{~g})$, and proteins (77-127 g). But these very significant variations in food intake did not bring about proportional changes in insulin requirements, glycosuria, or urine volume, as demonstrated by a covariance analysis. It is indispensable that diabetic children adjust for themselves their daily energy intake, following their individual appetites. Children do not have fixed energy requirements because they are growing and show inconstant physical activity. Growth retardation and the Mauriac syndrome, which are mentioned in your article, are no longer observed if we do not limit the energy intake or give fixed doses of insulin. ${ }^{9}$

Imposing a weighed and measured diet is of no real benefit and does not have any physiological basis. A restricted diet that controls only carbohydrate intake and thus favours fat intake is potentially dangerous to the vascular system. A total energy restriction inhibits growth. Moreover, the idea of "measuring" leads to rejection of the entire therapeutic regimen and to emotional problems. ${ }^{10}$ In addition, the incidence of retinopathy in relation to the duration of diabetes on a spontaneously balanced and adapted diet compares favourably with that on a restricted diet. ${ }^{11} 12$

In Belgium we teach diabetic children the principles of a diet deriving its energy as follows: $12-15 \%$ from protein, 30-35\% from lipid, and $50-55 \%$ from carbohydrate. This energy intake is divided between three principal meals and three snacks, varying with the activity of the child and according to the type of insulin used. ${ }^{13}$ The dose of insulin is adapted to the results of four daily analyses with Clinitest $2 / 10$ by the child himself, starting from the age of 10.1415

In conclusion, the treatment of infantile diabetes requires, above all, insulin therapy adapted to the child's needs. A fixed diet is uncalled for, as also are anarchic eating habits. The term "free diet," as opposed to the restricted diet which has long been the mainstay of diabetic treatment, should be changed to "spontaneously balanced and adapted diet."16 17

H DORCHY H LOEB

Department of Paediatrics,

University of Brussels,

Chr ERnOULd

Department of Paediatrics,

University of Liège,

Belgium

${ }^{1}$ Dorchy, H, and Loeb, H, fournal of Pediatrics. In press.

Ernould, C, et al, in Proceedings of the 3rd International Beilinson Symposium on

3 Dorchy, $\mathrm{H}$, et al, in Proceedings of the 2nd Annual Meeting of the International Study Group of Diabetes in Children and Adolescents, Belgium, 1976.

Toussaint, D, and Dorchy, H, Bulletin de la Société Belge d'Ophthalmologie, 1974, 168, 783 .

Somogyi, M, and Goldwasser, H V, American fournal of Medicine, 1959, 26, 165.

stradet, H, Dartois, A M, and Machinot, S, Annales de Pédiatrie, 1974, 21, 667.

p 385. Basel, Karger, 1975.

Mozin, M-J, et al, Acta Paediatrica Belgica. In press. Lestradet, H, and Megevand, A, in Diabetes in Fuveniles, ed $Z$ Laron, p 164. Basel, Karger, 1975.
Manciaux, M, Sardin, A M, and Hennion, E, Revue Manciaux, M, Sardin, A M, and Hennion, E, Revue
de Neuro-Psychiatrie Infantile, 1967, 15, 737.
estradet, $\mathrm{H}$, and Billaud, L, Presse Médicale, 1968, Lestradet,

76, 303.
François, R, Archives Françaises de Pédiatrie, 1976, 33,

Dorchy, H, Mozin, M-J, and Loeb, H, Revue Médicale de Bruxelles, 1975, 31, 391

Dorchy, $\mathrm{H}$, and Loeb, $\mathrm{H}$, Diabète et Métabolisme, $1975,1,87$.

Ernould, C, et al, Guide du feune Diabétique, vol 1. Liège, Revue Médicale de Liège, 1973

Manciaux, M, and Quetin, C, Pédiatrie, 1969, 24, 13. 7 Schmitt, B D, Clinical Pediatrics 1975, 14, 68.

\section{Danger of instant adhesives}

SIR,-In a contribution to the correspondence on this subject earlier this year (24 July, p 234) I drew attention to the possibility of a small child biting through a tube and smearing the glue on its lips and nose with the consequen possibility of suffocation. I was concerned that there did not seem to be any method of removing the adhesive from the skin or mucosa in a hurry. A letter from the manufacturers gave the impression that glue on the mucosa could be easily peeled with the aid of hot water, as hot as could be borne. A recent experience suggests that the hazard is very rea and the manufacturers' reassurances doubtful.

On 6 November a child of 2 years was seen in the accident department at Bath at $1 \mathrm{am}$. It had bitten into a tube of Super Glue 3 almost 12 hours earlier and was found with the glue smeared on its lip and teeth. Since then it had been peevish and distressed and would not go to sleep, though it did take some food. The child was brought to hospital as the parents were concerned. The tube was also brought and showed a tooth puncture (see figure).

The child resented examination and would not open its mouth. This caused concern, but when forcibly examined it was found that glue was adhering to the lower lip and the lower incisors, from where it could not be removed. It was quite impracticable in those circum-

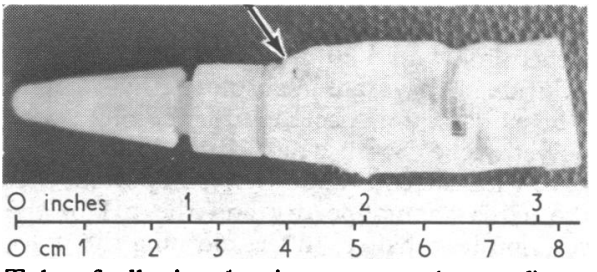

Tube of adhesive showing puncture (arrowed).

stances to attempt gentle peeling as suggested by the manufacturer or to use hot water. Once it was established that there was no crossadhesion between the jaws or lips the child was left alone and the parents reassured that the glue would eventually come away.

It is evident that one incisor punctured the tube and glue extruded on to those teeth and the adjacent lip. It is merely fortuitous that more did not exude and that cross-adhesion did not occur. This case illustrates that even after $12 \mathrm{~h}$ the bond remains firm. I feel more than ever convinced that this glue is a real risk to children and that nothing short of a tracheotomy is likely to save a child who is unfortunate enough to bond its lips and seal the nostrils, possibly with its hand.

C P DE FONSEKA

Accident Department,

Bath

\section{Treatment of axillary hyperhidrosis}

SIR,-I was interested to read in the short report by $\mathrm{Mr} \mathrm{E} \mathrm{C} \mathrm{Ashby} \mathrm{and} \mathrm{Mr} \mathrm{J} \mathrm{Ll} \mathrm{Williams}$ (13 November, $p$ 1173) that yet another weapon, cryosurgery, has been added to the armoury against axillary hyperhidrosis. It raises the question yet again of the efficacy of local treatment in the long-term control of axillary hyperhidrosis.

In a recent series five patients were subjected to Shelley's operation (local excision of the axillary skin), and all have had to undergo further treatment as their sweating became as bad as ever within six months. Mr Ashby and Mr Williams do not mention either the sex of their four patients nor the long-term results following axillary freezing, which it would be interesting to know in order to assess their techniques.

Four of our five patients were women who complained of excess sweating in the axilla only, although on examination they had more generalised hyperhidrosis. Recently we have had a male patient whose sweating was more localised to the axilla, and it is possible that some patients with hyperhidrosis may be amenable to local treatment rather than the conventional treatment of upper dorsal sympathectomy.

Department of Surgery,
Bristol Royal Infirmary,

Bristol

SIR,-I was interested to read the method for reducing axillary sweating by cryosurgery devised by $\mathrm{Mr}$ E C Ashby and $\mathrm{Mr} \mathrm{J} \mathrm{Ll}$ Williams (13 November, p 1173).

There is, however, a less traumatic procedure described by Shelley ${ }^{1}$ which I have found effective and which avoids any operative procedure. It has not been as widely publicised as it deserves, probably because there is some difficulty in making up the solution which is used and it was published in a book rather than 